\title{
Terminal Differentiation of Myogenic Cells Requires Stable Form of Tumor Suppressor Protein, P53
}

\author{
Bansidhar Datta \\ Department of Chemistry and Biochemistry, Kent State University \\ Kent, OH 44242 \\ bdatta@kent.edu
}

\begin{abstract}
Although, the role of tumor suppressor protein, 553 is well accepted in differentiation, it is not clear how p53 enhances differentiation in some cell lineages and inhibits others. C2C12 myoblasts permanently withdraw from cell cycle and terminally differentiate into multinucleated myotubes. BC3HI myogenic cells however differentiate but reversibly withdraw from cell cycle and do not fuse into myotubes. We examined the levels of p53 in both cytoplasm and nucleus of $\mathrm{C} 2 \mathrm{C} 12$ and $\mathrm{BC} 3 \mathrm{H} 1$ myogenic cells undergoing differentiation. We found quite a good amount of full-length p53 in the cytoplasm and extensive degradation in the nucleus of control and differentiated C2C12 myoblasts. In addition, in the nucleus we detected very low level of full-length p53 during early differentiation and quite a significant amount during late differentiation when C2C12 myoblasts were fusing into myotubes. On the other hand, we found quite a good amount of p53 in control and early differentiated BC3HI myogenic cells both in the cytoplasm and nucleus. However, its level gradually decreased in both locations while these cells were differentiating. Although, p53 is extensively degraded in the nucleus in these differentiated cells, this degradation pattern is quite different from C2C12 myoblasts, p53 mutant-expressing C33A cells, and testicular somatic (Leydig and Sertoli) cells. Altogether, our data indicate that the lack of differentiation of $\mathrm{BC} 3 \mathrm{H} 1$ cells in multinucleated myotubes is possibly due to the extensive degradation of 53 in the nucleus.
\end{abstract}

Abbreviations used: p53, a tumor suppressor protein; 8-Br-cAMP, 8-bromo-cyclic adenosine monophosphate; h, hour; and kDa, kilo-Dalton

Keywords: C2C12 myoblasts, BC3H1 myogenic cells, C33A cells, 10T1/2 mouse fibroblasts, tumor suppressor p53, cytoplasmic and nuclear distributions of $p 53$, degradation of $p 53$, and differentiation

\section{INTRODUCTION}

The tumor suppressor protein, p53 regulates cellular stress, cell cycle, and differentiation (1). In response to cellular stress, p53 is stabilized and activated via post-translational modifications such as phosphorylation and acetylation (2). During cellular stress conditions, p53 regulates the expression and activity of several cellular regulators, recruits them at the site of stress, and finally relieves the stress (3). If the stress is too extensive and not removable, p53 activates the apoptotic pathway to eliminate cells, which are under stress and possibly defective due to mutations and may have lethal effects to the organism (4). Due to its protective roles in cellular system, p53 is known as the guardian of the genome (5). In non-stress conditions, its level is maintained by proteosomal degradation via activation of MDM2 (1). p53 modulates cell cycle by regulating the expression and activity of retinoblastoma protein, $\mathrm{pRb}$, which binds to transcription factor, E2F and inhibits cell cycle progression (6-7). In certain cells it also induces the expression of cell cycle inhibitor, $\mathrm{p} 21^{\mathrm{cip} / \mathrm{waf}}$ that binds to cyclin/cyclin dependent kinase (CDK) complexes in all phases of the cell cycle and inhibits their activity (8). Activities of different cyclin/CDK complexes are required for transition of one phase to another during cell cycle progression (9). Although, p53's role in differentiation is well accepted, it is however not clear whether p53 facilitates or inhibits differentiation of myogenic cells (10-16). For example, in $\mathrm{C} 2 \mathrm{C} 12$ skeletal muscle differentiation wild type p53 upregulates the expression and activity of MyoD, which is one of the master regulators of differentiation - myogenin, Myf5, and MRF4 the others $(14,17,19)$ and thus facilitates $\mathrm{C} 2 \mathrm{C} 12$ myoblasts differentiation. In contrast, there are several other cell lineages, whose differentiation is negatively regulated by p53 (1213, 17). p53 knockout mice show an increased incidence of tumor formation in addition to a spectrum of developmental defects such as extencephaly, defective spermatogenesis, and skeletal abnormalities 
in a small percentage of animals $(10,18)$. Testicular somatic cells, Leydig and Sertoli cells carry out spermatogenesis (22-23). Several reports from past many years also showed diverse physiological functions of p53. Regulation of metabolic pathways such as glycolysis, oxidative phosphorylation, and fatty acid oxidation are among these functions of p53 (24-25).

Differentiation in culture of mouse $\mathrm{C} 2 \mathrm{C} 12$ myoblasts, which are originated from leg thigh muscles, is an excellent model to study molecular details of myogenesis during early differentiation and late terminal differentiation (26). While $\mathrm{BC} 3 \mathrm{H} 1$ myogenic cells derived from brain tumor undergo myogenesis but do not permanently withdraw from cell cycle and show terminal differentiation (2729). We therefore examined the cytoplasmic and nuclear levels of p53 in these two cell lines undergoing differentiation. We detected more full-length $\mathrm{p} 53$ in the cytoplasm of $\mathrm{C} 2 \mathrm{C} 12$ cells at their early stages of differentiation and slightly less full-length p53 during later stages of differentiation when myoblasts are fusing into myotubes. In contrast, during early stages of $\mathrm{C} 2 \mathrm{C} 12$ differentiation, extensive degradation of p53 was noticeable in the nucleus and a sharp increase of full-length p53 level during their fusion ( $72 \mathrm{~h}$ to $96 \mathrm{~h}$ ) into myotubes. On the other hand, the level of p53 decreases gradually both in the cytoplasm and nucleus of $\mathrm{BC} 3 \mathrm{H} 1$ cells undergoing myogenesis in differentiation medium and this decrease was more prominent in the cytoplasm as compared to the nucleus. In addition, two slightly faster migrating proteins possibly the degraded products of full-length $\mathrm{p} 53$ were detected in growing cells (0h) and during very early stage (24h) of differentiation. Their levels however decreased gradually during later stages of differentiation. We also noticed extensive degradation of p53 in human cervical carcinoma cell line C33A and no degradation in mouse 10T1/2 embryo fibroblasts. In testicular somatic cells like Leydig cells, full-length p53 and its possible degraded polypeptide running around $33 \mathrm{kDa}$ were detected, whereas, Sertoli cells showed no fulllength $\mathrm{p} 53$, instead its degraded product $33 \mathrm{kDa}$ polypeptide was the only protein present in this cell type. The distribution of $\mathrm{p} 53$ and its degraded product, $33 \mathrm{kDa}$ polypeptide in these testicular somatic cells did change when they were treated with 8-Br-cAMP, an inducer of PKA. Altogether, our data showed excellent correlation between the levels of full-length p53 and terminal versus non-terminal stages of myogenic cell differentiation.

\section{MAterials AND Methods}

All chemicals used in this study were obtained from Sigma Chemicals (St. Louis, MO), ICN Biomedicals, Inc. (Aurora, Ohio), Fisher Chemicals (New Jersey), and Merck (Darmstadt, Germany). Cell culture media, fetal bovine serum, horse serum, antibiotics-antimycotics, and insulin were from GIBCO-BRL (Rockville, MD).

\subsection{Cell Lines}

C2C12 murine thigh muscle myoblasts (ATCC-1172-CRL), C3H10T1/2 cloned murine embryo fibroblasts (ATCC-226-CCL) indicated as 10T1/2, human cervical carcinoma cell line C33A (ATCC, HTB-31), mouse testicular Sertoli cells (ATCC-1714 CRL) and Leydig cell (ATCC-1715 CRL), and BC3H1 mouse smooth muscle like brain tumor cells (ATCC-1443 CRL) were used in this study.

\subsection{Cell Growth and Differentiation}

Mouse $\mathrm{C} 2 \mathrm{C} 12$ myoblasts, 10T1/2 fibroblasts, and $\mathrm{BC} 3 \mathrm{H} 1$ smooth muscle cells were grown in Dulbecco's modified Eagle's medium (DMEM) supplemented with $20 \%$ fetal bovine serum (growth medium) under $5 \% \mathrm{CO}_{2}-95 \%$ air at $37{ }^{\circ} \mathrm{C}$. C33A cells were grown in DMEM supplemented with $10 \%$ fetal bovine serum. Mouse Leydig and Sertoli cells were cultured in DMEM plus HAM's F-12 medium (1:1) containing 2.5\% fetal bovine serum and 5\% horse serum in an incubator containing 5\% $\mathrm{CO}_{2}-95 \%$ air at $37{ }^{\circ} \mathrm{C}$. For differentiation, confluent cultures of $\mathrm{C} 2 \mathrm{C} 12$ or $\mathrm{BC} 3 \mathrm{H} 1$ cells were shifted from growth medium to differentiation medium containing $2 \%$ horse serum and $12 \mu \mathrm{g} / \mathrm{mL}$ of insulin, and allowed to differentiate for $96 \mathrm{~h}$. All cell culture media contained antibiotic-antimycotic containing 100 units $/ \mathrm{mL}$ of penicillin, $100 \mu \mathrm{g} / \mathrm{mL}$ of streptomycin, and $0.25 \mu \mathrm{g} / \mathrm{mL}$ of amphotericin B.

\subsection{Preparation of Cell Lysates, Determination of Protein Concentration, and Western Blotting}

For whole cell lysate preparation, cells were washed with phosphate buffer saline (PBS from GIBCO/BRL), harvested by scrapping, washed again with PBS, and RIPA buffer supplemented with a cocktail of protease inhibitors $(10 \mathrm{mg} / \mathrm{mL}$ each of leupeptin and aprotonin, $1 \mathrm{mM}$ sodium 
benzamidine, and $1 \mathrm{mM}$ PMSF) was added before freezing at $-80{ }^{\circ} \mathrm{C}$. For the preparation of cytoplasmic and nuclear fractions, cells were lysed by repeated vortexing in buffer A (50 mM Hepes, $\mathrm{pH} 7.6,150 \mathrm{mM} \mathrm{NaCl}$, and $0.5 \% \mathrm{NP}-40$ ) containing the above cocktail of protease inhibitors and microfused at high speed $(12,000 \mathrm{rpm})$ at $4{ }^{\circ} \mathrm{C}$ for $5 \mathrm{~min}$. Supernatants were stored as cytoplasmic fractions and to the pellets, RIPA buffer containing the cocktail of protease inhibitors was added, vortexed few times, and then microfuged at high speed $(15,000 \mathrm{rpm})$ at $4{ }^{\circ} \mathrm{C}$ for $15-20$ minutes to remove the cell debris. The supernatants saved as nuclear fractions. Protein concentrations were measured by Bio-Rad assays following the protocol supplied by the manufacturer (Bio-Rad). Equal amounts of total protein samples were loaded on 15\% SDS-PAGE followed by Western blot analysis using standard procedures.

\subsection{Antibodies}

A mouse monoclonal antibody (Ab-3), which recognizes the amino acid segment 212-217 of mutant and wild type p53 in Western blots, was from Oncogene Science. Anti-mouse secondary antibody against whole IgG conjugated with horseradish peroxidase was purchased from Amersham Corp. or Pierce. The blots were developed by the enhanced chemiluminescent (ECL) reagents came with the ECL kit from Pierce.

\section{RESUlTS AND DisCUSSION}

To examine the status of tumor suppressor protein, p53, during differentiation of $\mathrm{C} 2 \mathrm{C} 12$ myoblasts into myotubes, we prepared both cytoplasmic and nuclear total proteins at different times of differentiation. These proteins were then analyzed for the levels of p53 on Western blots (Fig. 1). In the cytoplasm, p53 showed some degradation at $0 \mathrm{~h}$ of differentiation generating a shorter peptide running around $33 \mathrm{kDa}$ region on SDS-PAGE (Fig.1A, lane 1). This degradation was not noticeable during $24 \mathrm{~h}$ and $48 \mathrm{~h}$ of differentiation (Fig. 1A, lanes 2-3) and therefore protein level increased slightly as compared to $0 \mathrm{~h}$. The level of p53 however declined about 50-60\% after $48 \mathrm{~h}$ of differentiation (Fig. 1A, lanes 4-5). In the nucleus, very low level of full-length p53 was detected at $0 \mathrm{~h}$ and $24 \mathrm{~h}$, not detectable at $48 \mathrm{~h}$, and significant amounts was found during $72 \mathrm{~h}$ and $96 \mathrm{~h}$ of differentiation of $\mathrm{C} 2 \mathrm{C} 12$ myoblasts (Fig. 1B, lanes 1-2, 3, and 4-5 respectively). In contrast, at least three slightly faster migrating peptides running around 40-48 $\mathrm{kDa}$ regions on SDS-PAGE were detected throughout the time of differentiation (Fig. 1B, lanes 1-5). In addition, extremely low level of $33 \mathrm{kDa}$ peptide was detected in the nucleus during the indicated time of differentiation of $\mathrm{C} 2 \mathrm{C} 12$ myoblasts as well. The nature of this group of peptides running slightly faster than the full-length p53 in the nucleus is not known. It is more likely that these peptides are the degraded products of p53 and possibly non-functional. The full-length p53 is intact in the cytoplasm and possibly functional while $\mathrm{C} 2 \mathrm{C} 12$ myoblasts are fusing into myotubes. During differentiation, C2C12 myoblasts usually start fusing into mytubes around $72 \mathrm{~h}$ to $96 \mathrm{~h}$ in differentiation medium and coincidently p53 level is very high in the nucleus (Fig. 1B, lanes 4-5) and low in the cytoplasm (Fig. 1A, lanes 4-5) during this time frame of differentiation. These results therefore indicate some role(s) of p53 during the fusion of $\mathrm{C} 2 \mathrm{C} 12$ myoblasts possibly to check the genomic integrity and/or preventing apoptosis of the multinucleated myotubes. It is however not known what role(s) it is playing in the cytoplasm during differentiation of $\mathrm{C} 2 \mathrm{C} 12$ myoblasts.

Four myogenic regulatory factors (MyoD, myogenin, Myf5, and MRF4) and MEF2 play a central role during conversion of myoblasts into myotubes $(14,17,19,30)$ and constitutive expression of any of these factors in fibroblasts turns on the myogenic cascade pathway $(14,17,19,30)$. However, a nonfusing cell line $\mathrm{BC} 3 \mathrm{H} 1$ (smooth muscle like brain tumor), which exhibits properties of smooth and skeletal muscles, contains functionally inactive MyoD but undergoes differentiation (28). To examine whether the expression of $\mathrm{p} 53$ is MyoD dependent while $\mathrm{BC} 3 \mathrm{H} 1$ cells were undergoing differentiation, these cells were cultured and allowed to differentiate in differentiation medium. Both cytoplasmic and nuclear extracts were prepared at different time intervals during the course of differentiation. Levels of p53 were measured by Western blots (Fig. 2). The results revealed that in the cytoplasm, p53 is quite abundant in control $\mathrm{BC} 3 \mathrm{H} 1$ cells growing in growth medium (Fig. 1A, 0h, lane 1) and its level gradually decreased during differentiation (Fig. 2A, lanes 1-5). The faster migrating $\sim 33 \mathrm{kDa}$ peptide was detected only during $0 \mathrm{~h}$ and $24 \mathrm{~h}$ of differentiation (Fig. 2A, lanes 12 ). In the nucleus however, plenty of p53 protein was present in control cells and cells at $24 \mathrm{~h}$ of 
differentiation (Fig. 2B, lanes 1-2). Its level started declining from $48 \mathrm{~h}$ until $96 \mathrm{~h}$ of differentiation (Fig. 2B, lanes 3-5). Two p53 like proteins appearing as a doublet running around $50 \mathrm{kDa}$ and $48 \mathrm{kDa}$ were also detected in a good amount in control and 24h differentiated BC3H1 cells (Fig. 2B, lanes 12). Their levels however started declining similar to the level of full-length 553 during $48 \mathrm{~h}$ to $96 \mathrm{~h}$ of differentiation (Fig. 2B, lanes 3-5). Surprisingly, the $33 \mathrm{kDa}$ peptide was not detected in the nucleus of these un-differentiated or differentiated $\mathrm{BC} 3 \mathrm{H} 1$ cells. It is not clear whether $50 \mathrm{kDa}, 48 \mathrm{kDa}$, and $33 \mathrm{kDa}$ proteins are the degraded products of $\mathrm{p} 53$ or some modified forms or splice variants of p53. Nonetheless, these results are quite different from the results we obtained from control and differentiated $\mathrm{C} 2 \mathrm{C} 12$ myoblasts (Fig. 1). Altogether, it is however clear that p53 may have inhibitory roles both in the cytoplasm and nucleus during differentiation of $\mathrm{BC} 3 \mathrm{H} 1$ cells.
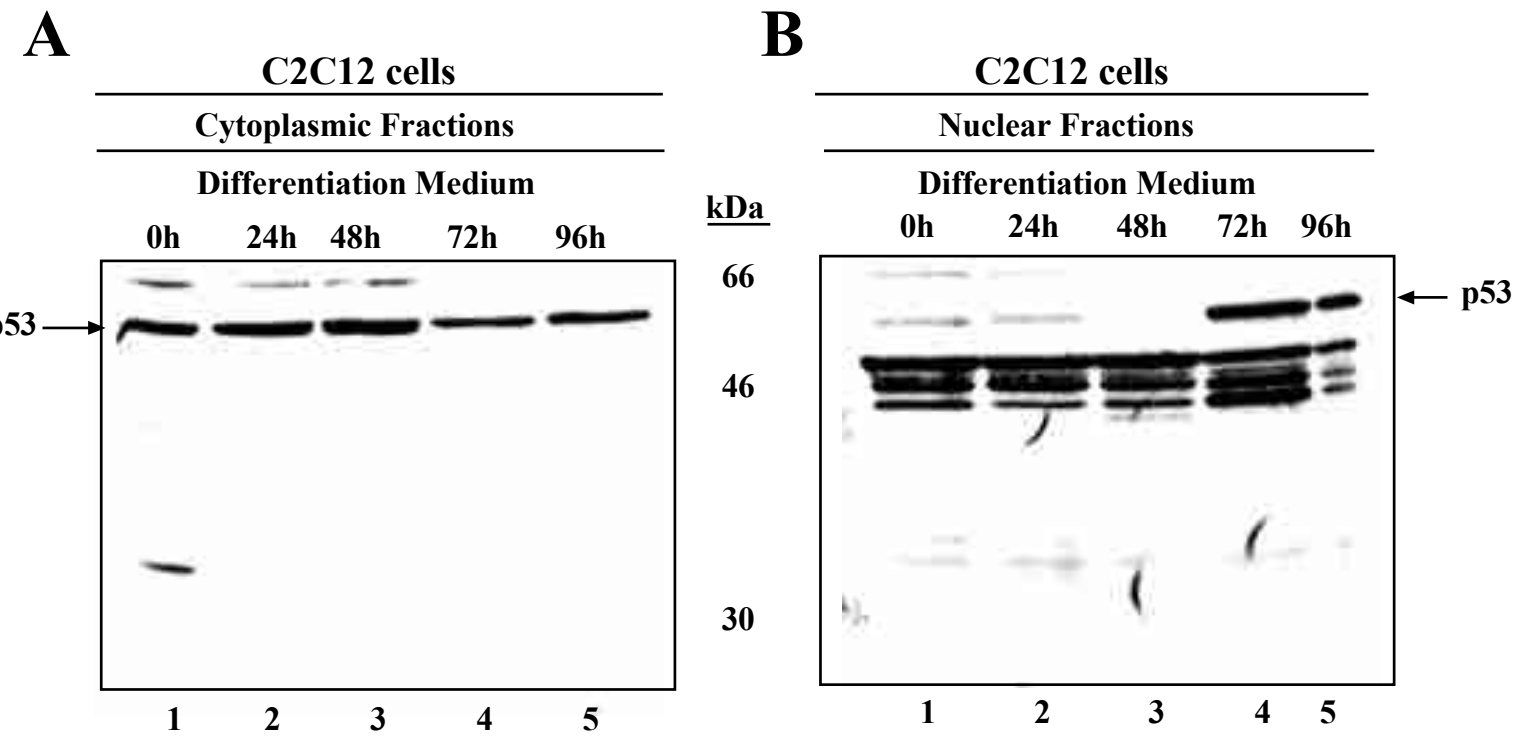

Fig1. Degradation of p53 in C2C12 myoblasts. C2C12 myoblasts were grown to confluence in growth medium then allowed to differentiate into myotubes in differentiation medium. At different time intervals cells were lysed, cytoplasmic fractions $(A)$ and nuclear fractions $(B)$ were prepared, $40 \mu \mathrm{g}$ of protein samples from different time points of differentiation were analyzed on a 15\% SDS-PAGE followed by immuno-blotting with a monoclonal antibody specific to p53. p53 band is marked by an arrow. The sizes (in kDa) of protein markers are shown in the middle.
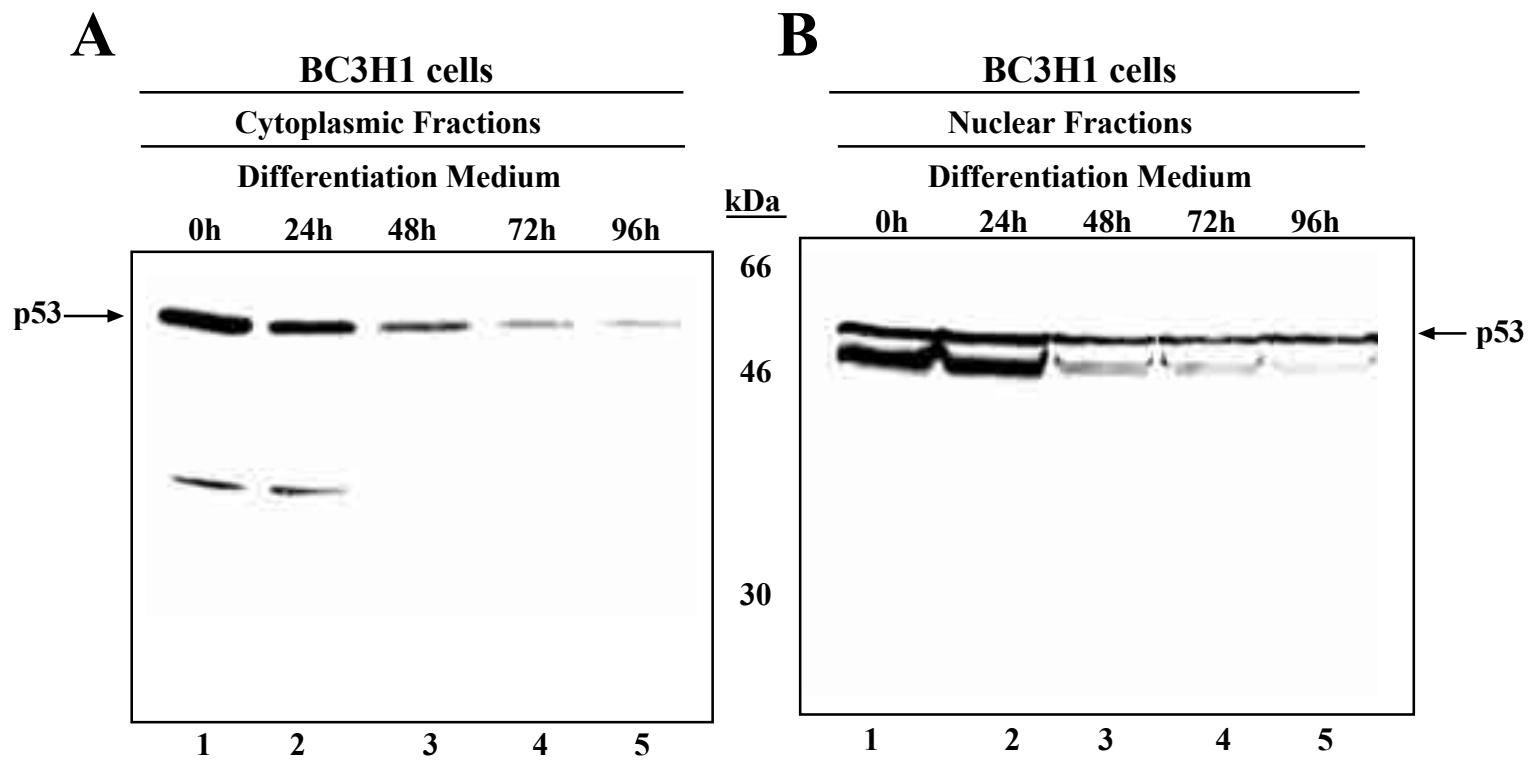

Fig2. Degradation of 553 in $\mathrm{BC3H1}$ cells. $\mathrm{BC} 3 \mathrm{H1}$ cells were grown in growth medium and allowed to differentiate into differentiation medium. At different times of differentiation cells were lysed, both cytoplasmic (A) and nuclear fractions (B) were prepared, and $40 \mu \mathrm{g}$ of protein samples from different time points were analyzed on Western blots using a monoclonal antibody specific to p53. An arrow marks p53 band. The sizes (in $k D a)$ of protein markers are shown in the middle. 
To further explore the existence of the faster migrating p53 like polypeptides in different cell types, human cervical carcinoma C33A cells and mouse embryonic 10T1/2 cells were cultured, cell lysates were prepared, and the level of p53 was analyzed on a Western blot (Fig. 3). In C33A cells, which express mutant p53 (31-32), there are several slower and faster migrating polypeptides, which could be detected by the same p53 monoclonal antibody. In these cells, the level of full-length p53 is very low and two faster migrating polypeptides running around $46 \mathrm{kDa}$ and $33 \mathrm{kDa}$ were expressed. The later polypeptide is most abundant as compared to the other (Fig. 3, lane 1). In contrast, none of these polypeptides except full-length p53 was detected 10T1/2 cells (Fig. 3, lane 2). The presence of the polypeptides, $46 \mathrm{kDa}$ and $33 \mathrm{kDa}$ in $\mathrm{C} 33 \mathrm{~A}$ cells is somehow in agreement with the detection of similar polypeptides in the nucleus of $\mathrm{C} 2 \mathrm{C} 12$ myoblasts either growing in growth medium or fusing into myotubes (Fig. 1). It is however not clear at present whether these polypeptides are the proteolytic products of p53 or they have originated from p53 transcript by using alternative translational initiation sites or p53 slice variants.

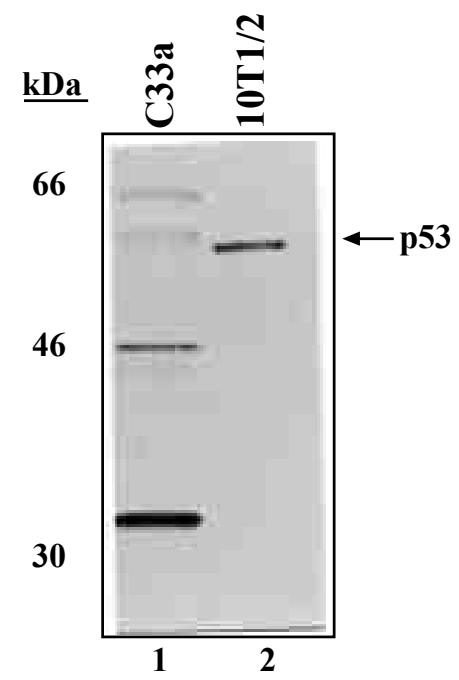

Fig3. Levels of p53 in C33A and 10T1/2 cells. These cells were grown, harvested and lysed. $40 \mu \mathrm{g}$ of whole cell extracts were analyzed on immuno-blot for the levels of p53 using a monoclonal antibody specific to p53. An arrow marks $p 53$ band. The sizes (in $k D a$ ) of protein markers are shown in the left.

To examine more details about the polypeptides, which were detected by the same p53 monoclonal antibody that can detect both mutant and wild type p53, we examined the p53 level in testicular somatic cells (Leydig and Sertoli). Apparently, these cells do not undergo frequent somatic mutations and therefore will have very little chance to have p53 mutant. Mammalian testis is divided into two compartments - the avascular seminiferous tubules consisting of Sertoli cells and germ cells, and the vascularized interstitial area, which contains Leydig cells (22-23). Leydig cells, under the control of luteinizing hormone (LH), produce androgens whereas, Sertoli cells, under the control of serum follicle-stimulating hormone (FSH) and locally produced testosterone provide the structural and functional environment for the initiation and maintenance of spermatogenesis (22-23). In response to LH, Leydig cells produce testosterone through a cAMP-signaling pathway (33-34). Testosterone is required for completion of meiosis and for differentiation of spermatids. We tested the levels of p53 in these testicular somatic cells (Leydig and Sertoli cells) untreated and treated with 8-Br-cAMP (Fig. 4), which activates protein kinase A (PKA). Activated PKA phosphorylates several regulatory proteins that are involved in cell cycle regulation (34). We found Leydig cells contain quite a good amount of p53 and its level decreased slightly when these cells were treated with 8-Br-cAMP (Fig. 4, compare lanes 2-4 with lane 1, panel "Leydig cells"). In contrast, Sertoli cells did not show any detectable level of full-length p53 whether they are untreated or treated with 8-Br-cAMP (Fig. 4, lanes 1-4, panel "Sertoli cells"). Surprisingly however, both these cell lines contain a $33 \mathrm{kDa}$ polypeptide almost in constant level whether cells were untreated or treated with 8-Br-cAMP. In Sertoli cells, this $33 \mathrm{kDa}$ polypeptide, which was detected by the same p53 monoclonal antibody, does not seem to be the proteolytic product of p53 rather an isoform originated from p53 transcript's slice variant or by using its different translational initiation site. 


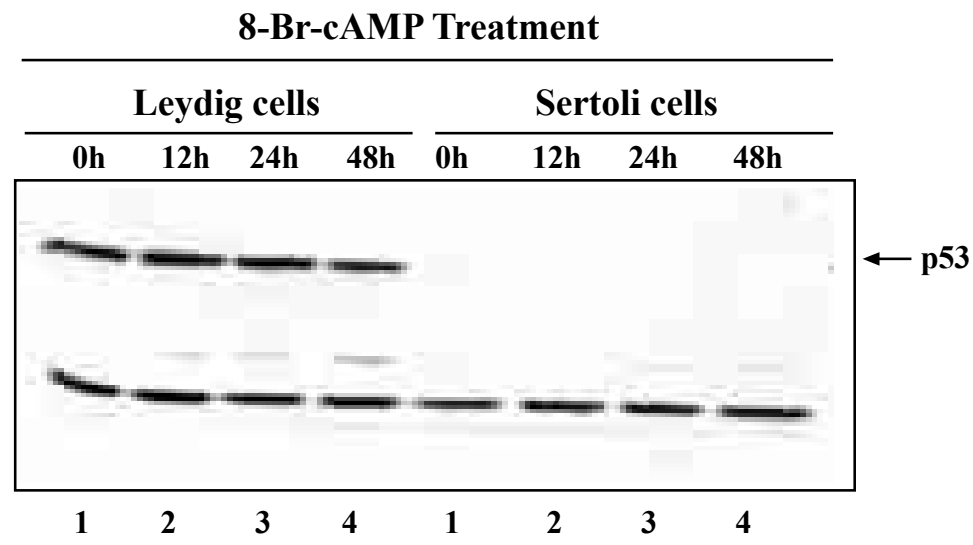

Fig4. Levels of p53 in Leydig cells and Sertoli cells treated with 8-Br-cAMP. Both mouse Leydig cells and Sertoli cells were grown to 40-50\% confluence, then treated with $1 \mathrm{mM} 8$-Br-cAMP for indicated times. Cell lysates were made at different time intervals of treatment and $40 \mu \mathrm{g}$ of proteins were analyzed on a Western blot using a monoclonal antibody specific to p53. An arrow marks p53 band.

During myogenesis $\mathrm{C} 2 \mathrm{C} 12$ myoblasts withdraw permanently from cell cycle and fuse into myotubes. On the other hand, $\mathrm{BC} 3 \mathrm{H} 1$ myogenic cells, which reversibly withdraw from cell cycle and differentiate into non-fusing cells. In these cells, there is no functional MyoD, although, they express Myf5, myogenin, MRF4, MEF2, and several other muscle-specific genes (28). p53's roles in differentiation are very puzzling. It enhances differentiation of some cells while inhibits differentiation of others. In differentiation of $\mathrm{C} 2 \mathrm{C} 12$ myoblasts, $\mathrm{p} 53$ has been shown to upregulate the expression and activity of $\mathrm{MyoD}$, one of the master regulators of myogenesis. The activity of MyoD is essential during early stages of differentiation to program cells for myogenic lineage and its activity declines at the later stages of differentiation, namely during the fusion of myoblasts into myotubes, where myogenin seems to be more active and absolutely required for terminal differentiation (18). p53 is also involved in physiological processes like glycolysis, oxidative phosphorylation, and fatty acid oxidation (24). In this study, we found p53 in cytoplasm of both $\mathrm{C} 2 \mathrm{C} 12$ myoblasts and $\mathrm{BC} 3 \mathrm{H} 1$ myogenic cells (Figs. $1 \& 2$ ). It is possible that this cytoplasmic population of p53, especially in $\mathrm{C} 2 \mathrm{C} 12$ myoblasts, may be involved in the regulation of their metabolic processes. In $\mathrm{BC} 3 \mathrm{H} 1$ tumor cells however, this may not be true, especially during the later stages of the differentiation. In $\mathrm{C} 2 \mathrm{C} 12$ myoblasts or myotubes, p53 is extensively degraded in the nucleus during all stages of differentiation. Its full-length is only detected in a high level at the later stages of differentiation (72h to 96h), namely during the fusion of myoblasts into myotubes, indicating its possible roles to enhance the expression and activity of myogenin, which is required for myoblasts fusion and terminal differentiation. In $\mathrm{BC} 3 \mathrm{H} 1$ myogenic cells undergoing differentiation, although full-length p53 is present during early stages of myogenesis, its level gradually declines at later stages of differentiation. This is possibly affecting the expression and activity of MyoD and that's why these cells do not terminally differentiate into myotubes. In addition, differentiated $\mathrm{BC} 3 \mathrm{H} 1$ cells express low levels of $\mathrm{p} 21^{\text {cip/waf }}$, the cell cycle inhibitor, GADD45, and tsp-I, all of whose expressions are p53-dependent (35) and this is possibly due to the lack of p53 (Fig. 2). Constitutive overexpression of p53 in BC3H1 myogenic cells will increase the expression and activity of these proteins along with MyoD that will program these cells for terminal differentiation.

\section{REFERENCES}

[1] Hu, W., Feng, Z. and Levine, A. J. (2012) The regulation of multiple p53 stress responses is mediated through MDM2. Genes \& Cancer 3, 199-208.

[2] Kruse, J. P. and Gu, W. (2009) Modes of p53 regulation. Cell 137:609-622.

[3] Inoue, K., Fry, E. A. and Frazier, D. P. (2016) Transcription factors that interact with p53 and Mdm2. Int. J. Cancer 138, 1577-1585.

[4] Vazquez, A., Bond, E. E., Levine, A. J. and Bond, G. L. (2008) The genetics of the p53 pathway, apoptosis and cancer therapy. Nat. Rev. 7, 979-987.

[5] Henrikson, S. and Farnebo, M. (2015) On the road with WRAP53: guardian of Cajal bodies and genome integrity. Front. Genet. 6, 1-10.

[6] Yamasaki, L. (2003) Role of the RB tumor supprssor in cancer. Cancer Treat. Res. 115, 209-239. 
[7] Porrello, A., Cerone, M. A., Coen, S. et al. (2000) p53 regulates myogenesis by triggering the differentiation activity of pRb. J. Cell Biol. 151, 1295-1304.

[8] Gartel, A. L., Serfas, M. S. and Tyner, A. L. (1996) p21-negative regulator of the cell cycle. Proc. Soc. Exp. Biol. Med. 213, 138-149.

[9] Malumbres, M. (2014) Cyclin-dependent kinases. Genome Biol. 15, 122-131.

[10] Donehower, L. A., Harvey, M., Slagle, B. L., McArthur, M. J., Montogomery, C. A. et al. (1992) Mice deficient for p53 are developmentally normal but susceptible to spontaneous tumors. Nature 356, 215-221.

[11] Saleem, A., Adhihetty, P. J. and Hood, D. A. (2009) Role of p53 in mitochondrial biogenesis and apoptosis in skeletal muscle. Physiol. Genomics 37, 58-66.

[12] Molchadsky, A., Shats, I., Goldfinger, N. et al. (2008) p53 plays a role in mesenchymal differentiation programs in a cell fate dependent manner. PLoS One 3, e3707.

[13] Molchadsky, A., Rivin, N., Brosh, R. Rotter, V. and Sarig, R. (2010) p53 is balancing development, differentiation and dedifferentiation to assure cancer prevention. Carcinogenesis 31, 1501-1508.

[14] Tamir, Y. and Bengal, E. (1998) p53 protein is activated during muscle differentiation and participates with MyoD in the transcription of muscle creatine kinase gene. Oncogene 17, 347356.

[15] Cam, H., Griesmann, H., Beitzinger, M. and Hofmann, L. (2006) p53 family members in myogenic differentiation and rhabdomyosarcoma development. Cancer Cell 10, 281-293.

[16] Solozobova, V. and Blattner, C. (2011) p53 in stem cell. World J. Biol. Chem. 2, 202-214.

[17] Braun, T., Bober, E., Buschhausen-Denker, G., Kohtz, S., Grzeschik, K. H., Arnold, H. H. and Kohtz, S. (1989) Differential expression of myogenic determination genes in muscle cells: possible auto-activation by the Myf gene products EMBO J. 8, 3617-3625.

[18] Miller, J. B. (1990) Myogenic programs of mouse muscle cell lines: expression of myosin heavy chain isoforms, MyoD1, and myogenin. J. Cell Biol. 111, 1149-1159.

[19] Miner. J. H. and Wold, B. (1990) Herculin, a fourth member of the MyoD family of myogenic regulatory genes. Proc. Natl. Acad. Sci. USA 87, 1089-1093.

[20] Velletri, T., Xie, N., Wang, Y., Huang, Y., Yang, Q., Chen, Q., Shou, P., Gan, Y., Cao, G., Melino, G., and Shi, Y. (2015) p53 functional abnormality in mesenchymal stem cells promotes osteosarcoma development. Cell Death and Disease 6, e1-9.

[21] Sah, V. P., Attardi, L. D., Mulligan, G. J., Williams, B. O., Bronson, R. T. et al. (1995) A subset of p53-deficient embryos exhibit exencephaly. Nat. Genet. 10, 175-180.

[22] Benton, L., Shan, L.-X. and Hardy, M. P. (1995) Differentiation of adult Leydig cells. J. Steroid Biochem. Mol. Biol. 53, 61-68.

[23] Griswold, M. D., Heckert, L. and Linder, C. (1995) The molecular biology of the FSH receptor. J. Steroid Biochem. Mol. Biol. 53, 215-218.

[24] Feng, Z. and Levine, A. J. (2010) The regulation of energy metabolism and the IGF-1/mTOR pathways by the p53 protein. Trends. Cell Biol. 20, 427-434.

[25] Park, J. Y., Wang, P. Y., Matsumoto, T., et al. (2009) p53 improves aerobic exercise capacity and augments skeletal muscle mitochondrial DNA content. Circ. Res. 105, 705-712.

[26] Yaffe, D. and Saxe, O. (1977) Serial passaging and differentiation of myogenic cells isolated from dystrophic mouse muscle. Nature 270, 725-727.

[27] Steenstrup. T. and Hannon, K. (2000) Isolation of a spontaneously fusing BC3H1 muscle cell line: fusion alters the response to serum stimulation. In vitro Cell Dev. Biol. 36A, 241-248.

[28] Sharp, S. B., Villalvazo, M., Huang, M., Gonzalez, R., Alarcon, I., Bahamonde, M., D'agostin, D. M., Damle, S., Espinosa, A., Han, S. J., Liu, J., Navarro, P., Salguero, H., Son, J. and Vu, S. (2002) Further characterization of BC3H1 myogenic cells reveals lack of p53 activity and underexpression of several p53 regulated and extracellular matrix-associated gene products. In Vitro Cell. Dev. Biol. 38, 382-393.

[29] Schubert, D., Harris, A. J., Devine, C. E. and Heinemann, S. (1974) Characterization of a unique muscle cell line. J. Cell. Biol. 61, 398-413. 
[30] Gossett, L. A., Kelvin, D. J., Sternberg, E. A., and Olson, E. N. (1989) A new myocyte-specific enhancer-binding factor that recognizes a conserved element associated with multiple musclespecific genes. Mol. Cell. Biol. 9, 5022-5033.

[31] Crook, T., Wrede, D. and Vousden, K. H. (1991) p53 point mutation in HPV negative human cervical carcinoma cell lines. Oncogene 6, 873-875.

[32] Etscheid, B. G., Foster, S. A. and Galloway, D. A. (1994) The E6 protein of human papilloma virus type 16 functions as a transcriptional repressor in a mechanism independent of the tumor suppressor protein, p53. Virology 205, 583-585.

[33] Waeber, G. and Habener, J. F. (1991) Novel testis germ cell-specific transcript of the CREB gene contains an alternatively spliced exon with multiple in-frame stop codons. Endocrinology 131, 2010-2015.

[34] Walker, W. H., Ficci, L. and Habener, J. F. (1995) Expression of the gene encoding transcription factor cyclic adenosine 3'-5'-monophosphate (cAMP) response element-binding protein (CREB): regulation by follicle-stimulating hormone-induced cAMP signaling in primary rat Sertoli cells. Endocrinology 136, 3534-3545.

[35] Dameron, K. M., Volpert, O. V., Tainsky, M. A. and Bouck, N. (1994) Control of angiogenesis in fibroblasts by $\mathrm{p} 53$ regulation of thrombospondin-1. Science $265,1582-1584$.

\section{AUTHOR's BIOGRAPHY}

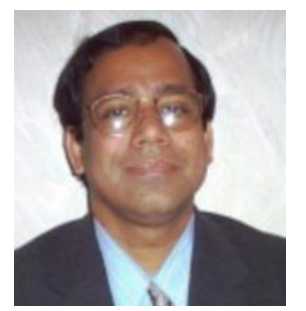

Bansidhar Datta, Ph.D., Associate Professor, Department of Chemistry and Biochemistry, Kent State University, Kent, OH 44240, USA 